\title{
A criação de tilápia no estado do Amapá como fonte de risco ambiental
}

\author{
Cecile de Souza GAMA ${ }^{1}$
}

RESUMO

O Estado do Amapá, apesar de apresentar condiçôes favoráveis ao crescimento da piscicultura, ainda apresenta pouco desenvolvimento desta atividade. A criação de peixes no Estado vem atraindo a atenção de muitos pequenos empreendedores que conseguem financiamento para tal, no entanto, seu investimento é concentrado na criação da Tilápia. Trata-se de uma espécie exótica, cujo processo de criação já foi amplamente estudado, mas que oferece risco de sua introdução no ambiente caso seja criada sem planejamento, como acontece no Amapá. A grande concentração de empreendimentos com criação de Tilápia no Estado se encontra em áreas ambientalmente frágeis, podendo causar danos ambientais em caso de soltura ou escape, que normalmente acontece. Como não existem estudos na região sobre o potencial dano ambiental causado por esses peixes, preventivamente deve-se evitar esse tipo de criação, uma vez que existem outras espécies possíveis de serem criadas que são nativas do ambiente, como o Tambaqui.

PALAVRaS-CHAVE: Tilápia, Amapá, Espécie exótica,

\section{The tilápia creation in the Amapá state as source of environmental risk}

\section{ABSTRACT}

The state of Amapá presents great conditions for aquaculture growth, but continues to present little development of this activity. The creation of fish in the State is attracting the attention of many small entrepreneurs who concentrate in creating Tilápia, an exotic species, whose process of creation has been widely studied. However, there is the risk of introducing it into the environment, if created without planning, as happens in Amapá. The heavy concentration of enterprises creating Tilápia in the State is located in fragile areas, which can cause environmental damages if it is let loose or escapes, which normally happens. As there are no studies in the region on the potential environmental damage caused by these fish, this type of creation must be prevented, since other possible species native to the environment, such as the Tambaqui, can be bred.

KEYWORDS: Tilápia, Amapá, Exotic species. 


\section{INTRODUÇÃO}

A piscicultura vem despertando um interesse crescente por parte de pequenos e médios empresários em todo país por se tratar de um empreendimento que tem seu produto final com uma alta taxa de aceitação pelo mercado.

É reconhecido que o Estado do Amapá possui grande potencial para o desenvolvimento da aqüicultura, por contar com uma ampla variedade de espécies de peixes, disponibilidade de recursos hídricos e clima propício, relativamente constante ao longo do ano, o que levaria a uma produção continuada, sem períodos de entressafra, como acontece nos principais pólos aqüicultores situados na região Sudeste. Estas características fazem com que esta atividade, potencialmente, tenha grande importância no que diz respeito à sustentabilidade ecológica, econômica e nutricional.

Apesar de todas as potencialidades da região, o Amapá é um dos estados brasileiros onde a aqüicultura encontra-se menos desenvolvida. A falta de política direcionada para a atividade não permitiu que se alcançassem melhores níveis de crescimento. As iniciativas privadas encontram dificuldades de ordem técnica e financeira para progredirem em empreendimentos maiores. Algumas dificuldades, no entanto, já podem ser destacadas, como o isolamento do Estado, a precariedade em termos de infra-estrutura e a conseqüente dificuldade de transporte para o escoamento da produção, falta de acesso aos insumos, que, quando obtidos, chegam a um custo muito elevado, falta de mão de obra qualificada, entre outros aspectos. Fez-se necessário, então, um estudo detalhado do quadro atual da piscicultura, com relação inclusive aos aqüicultores novos e em potencial, para que essas dificuldades sejam melhor identificadas e equacionadas soluçōes para o crescimento efetivo da atividade no Estado, em bases que possibilitem sua sustentabilidade ao longo do tempo, nos aspectos econômicos, sociais e ambientais.

A grande facilidade de reprodução da Tilápia estimula os criadores a adquirirem esta espécie e povoarem seus tanques, porque com um baixo investimento, logo eles têm seus tanques repletos de peixes. Além disso, a Tilápia constitui uma espécie rústica que ocorre numa ampla gama de variações ambientais, suportando limites extremos de temperatura e oxigênio bem como a presença de poluentes de natureza variada (Beyruth et al., 2004).No entanto não há um planejamento para se evitar a superpopulação dos tanques e a falta de alimento para o desenvolvimento dos peixes, que constituem fatores limitantes para o sucesso da criação, além da perda de indivíduos, seja por ataque de predadores ou através do escape destes através de enchentes no período chuvoso ou pelo escoamento e abastecimento d'água.

Os dejetos liberados pelos peixes modificam as características físicas, químicas e biológicas do tanque ou viveiro. Esses resíduos orgânicos, após ação microbiológica, fornecem nutrientes essenciais para o desenvolvimento de plâncton e de macrófitas aquáticas, podendo, quando em excesso, causar eutrofização do ambiente e alteração da composição e abundância de diversos organismos aquáticos (Pádua, 2001). Kestmont (1995) reuniu informaçôes sobre efeitos negativos que a aqüicultura em geral exerce sobre o meio ambiente biológico, destacando: alteração dos valores da temperatura da água; aumento da demanda química e bioquímica de oxigênio e da concentração de fósforo e sólidos em suspensão; diminuição da concentração de oxigênio dissolvido; contaminação com produtos químicos; acúmulo de sedimento rico em matéria orgânica; poluição e erosão; e aumento do risco de disseminação de doenças.

\section{METODOLOGIA}

Este estudo fez parte de um projeto financiado pelo PROBEM-MMA e executado pelo IEPA (Instituto de Pesquisas Científicas e Tecnológicas do Estado do Amapá), denominado "Diagnóstico da Pesca e Aqüicultura do Amapá" que tinha como objetivo levantar dados básicos sobre o estado dessas atividades no que diz respeito à produção, entraves e perspectivas futuras para servir como subsídio a formulação de políticas para seu desenvolvimento.

Os dados foram obtidos através da aplicação de um questionário a cada aqüicultor encontrado. Para encontrar os aquicultores, foram consultados cadastros no IBAMA, SEMA (Secretaria de Estado do Meio Ambiente), SEAF (Secretaria de Estado da Agricultura, Pesca, Floresta e Abastecimento), AQUIAP (Associação dos Aqüicultores do Estado do Amapá), RURAP (Instituto de Desenvolvimento Rural do Amapá), BASA (Banco da Amazônia), além de aqüicultores encontrados através de busca e informações levantadas pelos próprios entrevistadores durante as entrevistas. Foram levantados dados em todas as regióes do Estado durante os anos de 2001 e 2002, através de visitas aos empreendimentos. Em alguns locais havia a intenção de se iniciar um cultivo com a utilização de tanques-rede, mas como não havia sido iniciado até o momento das entrevistas, os dados coletados foram referentes ao sistema de cultivo convencional, em geral, com tanques cavados na terra firme ou cavados em áreas de várzea para aproveitar a disponibilidade de água ou através do uso de cercas nos corpos d'água (Figura 1)

Nos questionários eram feitas perguntas aos aqüicultores acerca das espécies criadas, tipo e características da criação, tempo de existência do empreendimento, se já sofreu algum tipo de dano ambiental e perda de peixes ao ambiente, tipo e frequiência de alimentação, dados acerca da comercialização dos peixes, com o objetivo de obter uma caracterização completa de cada empreendimento visitado. 


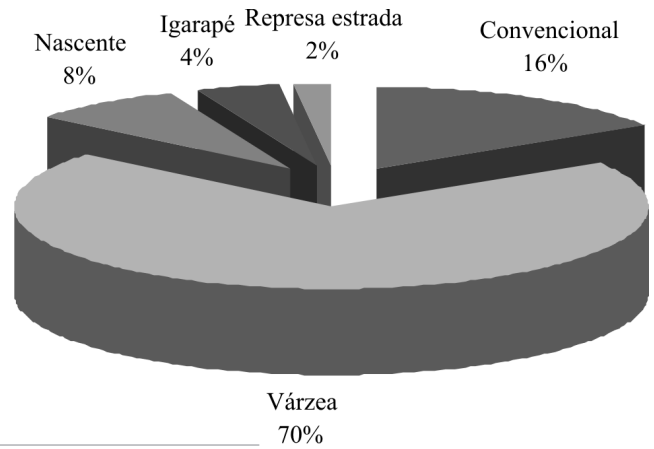

Figura 1- Ambientes de criação de Tilápia no Estado do Amapá.

Foram realizadas 92 entrevistas com aqüicultores em todo o Estado de forma a se obter resultados amostrais o mais próximo possível da realidade. $57 \%$ da criação de peixes analisada neste estudo é proveniente de Macapá e Porto Grande (Figura 2). Destas entrevistas, foi obtido um total de 147 tanques que já apresentavam peixes em criação no momento da entrevista. Dentre os entrevistados haviam 14 propriedades que se encontravam em construção ou com tanques vazios ou sem peixes.

Além do preenchimento dos questionários pelos aqüicultores, todos os tanques foram georreferenciados $\mathrm{e}$ fotografados a fim de se registrar a grande diversidade de formas de criação encontrados.

Os dados referentes à criação de Tilápia foram tratados separadamente e posteriormente inseridos no contexto geral da atividade piscicultora do Estado do Amapá.

\section{RESULTADOS E DISCUSSÃO}

No Amapá foi constatado que existe a criação das três espécies de Tilápia introduzidas no Brasil (Oreochromis niloticus (Linnaeus, 1758), Tilapia rendalli (Boulenger, 1897), Sarotherodon urolepis hornorum (Trewavas, 1966)). Em alguns casos, principalmente por falta de conhecimento, o criador coloca mais de uma espécie em consórcio no mesmo tanque.

Dentre os 92 aqüicultores entrevistados, 54\% afirmaram cultivar a Tilápia. Este fato não seria tão preocupante se não fossem consideradas as condições nas quais é realizado este cultivo. Segundo as entrevistas, foram liberados 144.580 alevinos de Tilápia em tanques espalhados em todo o Estado, sendo que $46 \%$ destes tanques estão localizados no município de Porto Grande (Figura 2), onde se encontram as nascentes de dois importantes rios do Estado, o Matapi e o Pedreira, além do município ser cortado pelo rio Araguari (Figura 3). Este grande número de criadores é principalmente devido à grande atividade produtora da colônia agrícola do Matapi que fica no entorno da nascente do rio Matapi, além desta área ser cercada por inúmeros igarapés que irão formar este rio. Os municípios de Pedra Branca do Amapari e Mazagão aparecem em seguida como grandes produtores de Tilápia. Vale ressaltar que apesar do município de Macapá não se encontrar entre os grandes criadores de Tilápia, esse fato pode estar mascarado, visto que devido às proporções do município apenas foi feita uma amostragem, enquanto que nos outros municípios foi realizado um censo.

Com o potencial desenvolvimento da aqüicultura no Estado, é necessário se preocupar primeiramente com a questão ambiental, principalmente por se tratar de empreendimentos que interagem diretamente com o meio ambiente estando localizados muito próximos aos corpos d'água e nascentes, inclusive próximos a áreas de proteção e o uso não controlado desse corpo d'água, assim como o efluente não tratado do tanque/viveiro, podem causar impacto negativo nos recursos hídricos (Castellani \& Barrella, 2005). Um déficit na qualidade de água que pode ser causado por maus criadores que não se preocupam em manter intactas as fontes de água a jusante de seus empreendimentos pode vir a causar um prejuízo ambiental muito grande, impossibilitando o estabelecimento de vários organismos essenciais à cadeia alimentar, seja pelo alto grau de eutrofização do ambiente ou pela introdução de espécies exóticas. Tudo isto pode causar um impacto social muito grande, pois o peixe, aquele nativo das principais fontes d'água, constitui a base da alimentação da população amapaense, o que leva a supor que, caso a atividade piscicultora não seja bem planejada em todos seus aspectos, quando incentivada, pode gerar benefícios a alguns poucos que têm condiçôes de investir neste tipo de empreendimento e causar danos muito maiores àqueles que dependem do peixe em seu ambiente natural para seu sustento.

Muitas são as espécies de peixes criadas no Amapá. 62 \% dos tanques analisados apresentaram tambaqui (Colossoma macropomum), destes, $37 \%$ continham o tambaqui com uma ou mais espécie de peixes, sendo que $21 \%$ combinava o tambaqui com a Tilápia. Além desses, outros 33\% apresentavam a Tilápia exclusivamente ou em combinação com outras espécies (Figura 4). Outros peixes criados, com exceção

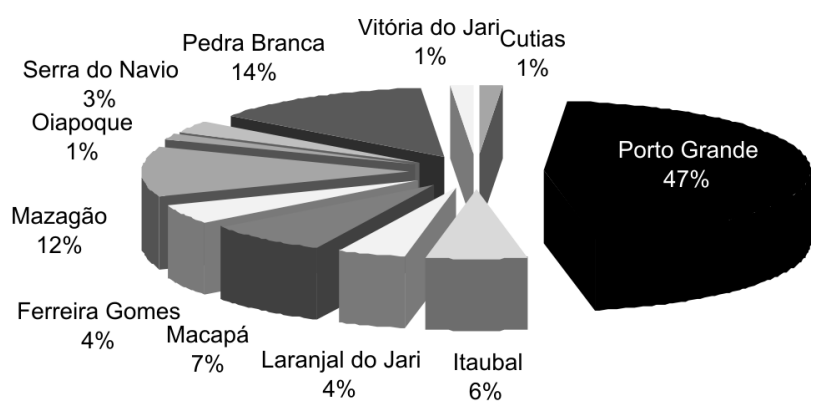

Figura 2- Distribuição dos empreendimentos aquicultores nos municípios do Estado do Amapá. 
da carpa que, como a Tilápia, que é uma espécie exótica, e do tambacu que constitui um híbrido entre o tambaqui e o pacu, são encontrados no ambiente e chegam aos tanques seja intencionalmente ou por acaso, principalmente pela falta de isolamento do tanque com o meio por meio de telas. Os peixes encontrados sob criação foram o acará catitu (Geophagus surinamensis), mafurá (Serrasalmus denticulatus), traíra (Hoplias malabaricus), jeju (Hoplerythrinus sp.), apaiari (Astronotus ocellatus), pratinha (Metynnis sp.), Curimatá (Curimatidae), tamoatá (Hoplosternum sp., Callichthys sp. Megalechis sp.), aracu branco (Leporinus sp.), bacu (Doradidae), e o pirarucu (Arapaima gigas). Muitos desses peixes são indesejáveis à criação, pois são predadores e causam danos muito sérios ao empreendimento.

No Amapá, $70 \%$ dos tanques com Tilápia se encontram em áreas de várzea e destes, $26 \%$ já tiveram parte de seu estoque liberado ao meio devido a enchentes e outros 37\% não possuem nenhum tipo de tela no escoamento dos tanques. Cerca de $4 \%$ dos tanques são feitos dentro de igarapés e $8 \%$

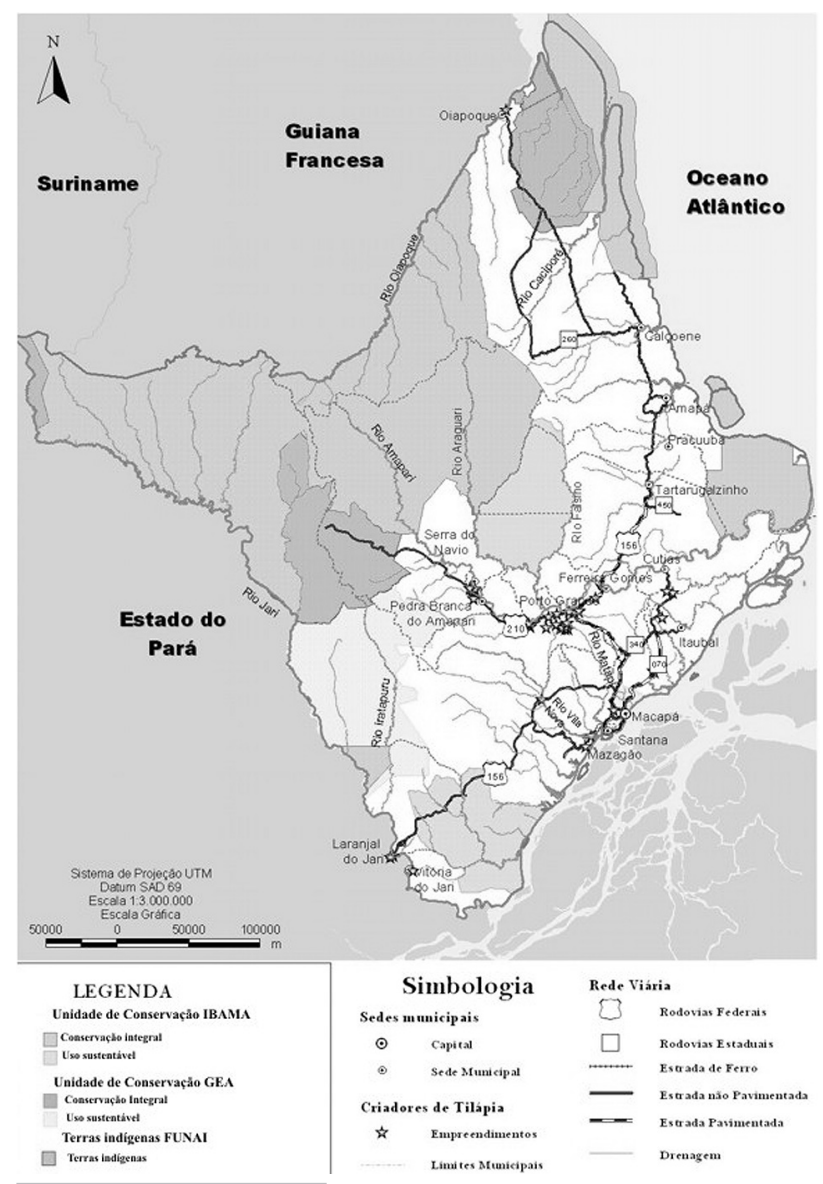

Figura 3 - Mapa do Estado do Amapá com a localização dos empreendimentos criadores de Tilápia analisados. Fonte: Convênio PROBEM/IEPA-CPZG e COT/ IEPA. se utilizam de nascentes de igarapés. Destes últimos, em 50\% dos casos já aconteceram solturas para o corpo d'água.

Apenas 40\% dos entrevistados afirmaram não ter sofrido nenhum tipo de dano ambiental. Como dano ambiental, podemos citar o problema de secas, enchentes e predadores. $40 \%$ sofreram danos com predadores como ariramba (Chloroceryle amazona, Ceryle torquata), garça (Casmerodius sp.), jacaré (Caiman sp., Paleosuchus sp.), lontra (Lontra longicaudis), socó (Ardeidae), bem-te-vi (Pitangus sulphuratus), Odonata, sucuri (Eunectes sp.), gavião (Falconiformes), mucura (Didelphis sp.), arapapá (Cochlearius cochlearius), maçarico (Charadriformes), gaivota (Laridae), sapo, mussum (Symbranchus marmoratus), traíra (Hoplias sp.), barata d'água (Hemiptera), jacundá (Crenicichla sp.), mergulhão (Podicipedidae), jeju (Hoplerythrinus sp., Erythrinus sp.), poraquê (Electrophorus electricus) e morcegos. 12\% já sofreram com prejuízos causados por enchentes, seja por chuva forte que aumenta o nível do reservatório causando o transbordamento, ou por inundação do corpo d'água, este último fator ainda é mais grave quando são utilizadas represas e telas dentro de igarapés. Os predadores que entram nos tanques causam danos tão grandes à criação que mesmo num tanque em Serra do Navio, onde foram colocadas 90 Tilápias de $10 \mathrm{~cm}$ esperando que elas se reproduzissem e povoassem os tanques, devido à presença de predadores no tanque como jacundá (Crenicichla sp.), uéua (Acestrorhynchus sp.) e traíra (Hoplias malabaricus), apenas sobraram 10 peixes entre 20 e $30 \mathrm{~cm}$. O proprietário não sabe como esses predadores apareceram no tanque, pois ele afirmou que o tanque nunca sofreu enchente, mas como o tanque não apresentava nenhuma tela na entrada de água pode-se concluir que os predadores conseguem entrar nos tanques e da mesma forma os indivíduos criados também conseguem sair dos mesmos.

Um dos fatores que desestimula a criação de outros peixes diferentes da Tilápia é que, por exemplo, muito dizem que o

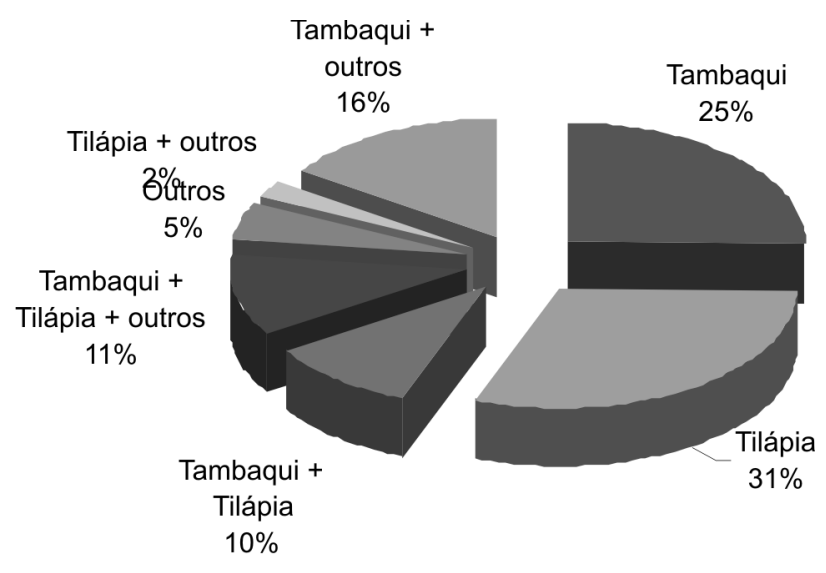

Figura 4- Espécies de peixes encontradas nos tanques analisados. 
tambaqui oferece pouco retorno. Os criadores reclamam do preço da ração e dizem que necessitariam de uma alimentação mais barata, pois o tempo necessário para o tambaqui alcançar um tamanho satisfatório para a venda é maior que no caso da Tilápia.

Mesmo com o grande incentivo que existe no Estado para a criação da Tilápia existem aqüicultores que reclamam de sua criação. Um entrevistado afirmou que não criaria mais a Tilápia, depois de já ter tentado e se decepcionado. Ele afirmou que mesmo com um ano e meio de criação, a Tilápia não alcança $1 \mathrm{~kg}$. Isso acontece com todos os criadores de Tilápia do Estado, pois todos os alevinos adquiridos que chegam ao Amapá não são revertidos sexualmente e segundo Leonhardt \& Urbinati (1999) os machos revertidos sexualmente apresentam incremento em peso diário acima do observado para machos sexados, no entanto, deve-se sempre considerar a densidade de cultivo, o ambiente de cultivo, o regime alimentar e outros fatores que possam interferir no incremento diário em peso dos peixes. Como a Tilápia é uma espécie que começa a se reproduzir em muito pouco tempo, quando são cultivados machos e fêmeas no mesmo tanque, logo eles estão superpovoados, causando uma falsa sensação de satisfação ao criador, pois ele não tem recurso para alimentar um número tão grande de peixe e nem espaço para que os eles se desenvolvam, aumentando a biomassa do tanque, mas diminuindo o valor comercial dos peixes como observado por Mainardes-Pinto et al. (2007). Beyruth et al. (2004) realizaram estudos sobre alimentação de Oreochromis niloticus em tanques de terra e observaram que apesar do arraçoamento, os alimentos naturais foram utilizados em proporçôes consideráveis pela espécie cultivada, mostrando a importância de se manter um ambiente de criação estável. No município de Serra do Navio um produtor liberou 230 indivíduos de Tilápia em seu tanque, que na verdade era uma represa dentro do igarapé e mesmo tendo muitos predadores e tendo sofrido perda de peixes com uma enchente, após cerca de um ano da liberação dos peixes que estavam sendo devidamente alimentados durante esse período, o criador estima que possui cerca de 6.000 exemplares de Tilápia.

Apesar de a criação de Tilápia ser ilegal, pois se trata de um peixe exótico e que deve ser portanto desestimulado, principalmente por existir uma quantidade muito grande de peixes nativos, de fácil criação e de boa aceitação no mercado, como é o caso do tamoatá, do acará e do aracu, por exemplo, ainda existem vários projetos sendo aprovados com financiamento público para a produção desses peixes, inclusive em propriedades públicas como escolas famílias agrícolas. Além disso, ainda existem casos como o de um criador que depois de ter todos seus peixes mortos devido a um parasita que os atacou, ganhou da prefeitura de seu município 80 indivíduos de Tilápia para recomeçar a sua produção.
Nenhum dos criadores entrevistados se preocupou em adquirir exemplares sexualmente revertidos, deixando que se reproduzam continuamente em seus tanques e em casos de solturas, são liberados exemplares em todos os estágios de desenvolvimento. Isto parece não incomodar muito os criadores, pois muitos acham que seria um muito bom se a Tilápia povoasse os corpos d'água da região. Muitas das solturas registradas foram feitas intencionalmente segundo esta perspectiva como também foi observado por Castellani \& Barrella (2006) na bacia do rio Ribeira de Iguape, SP, onde os peixes eram liberados ao ambiente seja por decisão do piscicultor ou por inundações devido ao alto regime pluviométrico da região. Este ato é considerado muito grave e segundo a lei 9.605 de 12 de fevereiro de 1998, Capítulo V, artigo 31, da Legislação Brasileira do Meio Ambiente, é considerado crime ambiental introduzir espécime animal no País, sem parecer técnico oficial favorável e licença expedida por autoridade competente, podendo conferir a pena de detenção por 3 meses a um ano e multa (Rocco, 2002). A introdução de espécies exóticas em reservatórios brasileiros foi recomendada durante as décadas de 1960-70 visando medidas profiláticas no combate aos vetores de algumas doenças tropicais. Mais recentemente essas introduçôes passaram a ter outros enfoques, como o fornecimento de proteína de boa qualidade e de baixo custo, além da melhoria da qualidade da água de reservatórios que têm como principal finalidade o abastecimento de centros urbanos (Barbieri et al., 2000). A falta de conhecimento é a principal causa destes atos. Muitas vezes os produtores não são informados sobre a possibilidade de se adquirir exemplares revertidos e muito menos sobre possíveis danos ao meio ambiente. As pessoas que incentivam a criação de Tilápia no Estado costumam afirmar que "seria ótimo se todos os rios do Estado fossem povoados por Tilápia”, não se preocupando com as consequiências que isto pode causar à sua biodiversidade. A falha no processo de introdução traz impactos desastrosos ao ecossistema ao invés de benefícios (Minns \& Cooley, 1999). Muitas introduções têm produzido poluições biológicas ao longo do mundo, degradando os frutos da evolução.

Esta preocupação com introduções de peixes oriundas de atividades piscicultoras tem aumentado em todo o mundo. A FAO (1995) ressalta que por causa da alta probabilidade dos impactos causados pela introdução de espécies serem irreversíveis e imprevisíveis, muitas introduções de espécies não são desejáveis por precaução.

Segundo Castellani \& Barrella (2006), A alteração da composição da fauna ictíica pela introdução de peixes exóticos, alguns do quais carnívoros e de grande voracidade, pode ser considerada preocupante. Pescadores artesanais entrevistados em Registro (SP) afirmaram ter capturado bagre-africano (Clarias gariepinus) junto com cardume de manjuba, e que no 
estômago de um bagre-africano havia 19 manjubas. Outros pescadores atribuem a recente diminuição do sagüiru e de pequenos bagres nativos à predação por espécies exóticas.

\section{CONCLUSÃO}

Pode-se concluir que o risco ambiental dos empreendimentos visitados é muito grande principalmente devido à localização dos tanques. A falta de recursos faz com que os criadores procurem áreas próximas a corpos d'água, que seria completamente aceitável caso fossem tomadas medidas preventivas para evitar impactos ambientais. Grande parte dos tanques são construídos em ambientes de várzea, que são muito frágeis por apresentarem contato direto com o corpo d'água. Além disso ainda foram encontrados tanques construídos em ressacas, nascentes de rios e o mais preocupante que seria o caso de pessoas que fecham igarapés e lagos com algum tipo de tela e jogam os peixes diretamente dentro destes corpos d'água, tornando visível o impacto que pode estar sendo causado por tais atos.

Apesar de a Tilápia não conseguir resistir num tanque com muitos predadores, não é possível afirmar que, quando solta no ambiente, esta não se estabeleceria. São necessários estudos nos locais onde houveram as introduçōes registradas para a definição do impacto causado no ambiente por esta espécie.

O desenvolvimento de piscicultura com a utilização de espécies nativas pode ser visto como um impacto positivo, portanto faz-se necessário um trabalho de incentivo à criação destes peixes e, conseqüentemente, ao uso de boas práticas nesse tipo de empreendimento.

\section{BIBLIOGRAFIA CITADA}

Minns, C. K.; J.M. Cooley. 1999. Intentional Introductions: Are the Incalculable Risks Worth It? In: Claudi, R.; Leach, J. H. (eds.). Nonindigenous freshwater organisms: vectors, biology and impacts. Boca Raton. Lewis Publisher. pp. 57-60

Rocco, R. 2002. Legislação Brasileira do Meio Ambiente. Rio de Janeiro, DP\&A Editora. 283p.

Beyruth, Z.; Mainardes-Pinto, C. S. R.; Fusco, S. M., Faria, F. C.; Silva, A. L. 2004. Utilização de alimentos naturais por
Oreochromis niloticus em tanques de terra com arraçoamento. B. Inst. Pesca, São Paulo, 30(1): 9 - 24.

Barbieri, G.; Teixeira-Filho, A. R.; Campos, E. C., Vermulm Jr., H.; Giamas, M. T. D. 2000. Biologia populacional da Tilápia Oreochromis niloticus, da represa de Guarapiranga, São Paulo - III. Atividade alimentar. B. Inst. Pesca, São Paulo, 26(1): 15-17.

Castellani, D.; Barrella, W. 2005. Caracterização da piscicultura na região do Vale do Ribeira, SP. Ciência e Agrotecnologia, Lavras, 29(1): 168-176.

Pádua, H.B. 2001. Impacto ambiental: um impacto na aqüicultura. Revista Brasileira de Agropecuária, 1(12): 1-66.

Mainardes-Pinto, C. S. R.; Paiva, P.; Verani, J. R.; Andrade-Talmelli, E. F.; Wirz, M. V. M. A.; Silva, A. L. 2007. Desempenho produtivo da tilápia tailandesa, Oreochromis niloticus, estocada em diferentes quantidades de tanques-rede instalados em viveiros povoados com a mesma espécie. B. Inst. Pesca, São Paulo, 33(1): $53-62$.

Leonhardt, J. H.; Urbinati, E. C. 1999. Estudo comparativo do crescimento entre machos de tilápia do nilo, Oreochromis niloticus, sexados e revertidos. Boletim do Instituto de Pesca, São Paulo, 25 (único): 19 - 26.

Kestmont, P. 1995. Different system of carp production and their impacts on the environment. Aquaculture, Amsterdam, 129: 347-372.

Recebido em 28/03/2006

Aceito em 10/06/2008 